\title{
Ion Microbeam Analysis in cultural heritage: application to lapis lazuli and ancient coins
}

\author{
Alessandro Lo Giudice ${ }^{1,2}$, Alessandro $\mathrm{Re}^{1,2}$, Debora Angelici ${ }^{2,3}$, Jacopo Corsi ${ }^{1,2}$, Gianluca Gariani ${ }^{1}$, Marco \\ Zangirolami ${ }^{1}$, Emma Ziraldo ${ }^{1}$
}

${ }^{1}$ Dipartimento di Fisica, Università di Torino, Via Pietro Giuria 1, 10125, Torino, Italy

${ }^{2}$ INFN Sezione di Torino, Via Pietro Giuria 1, 10125, Torino, Italy

${ }^{3}$ TecnArt S.r.l., Via pietro Giuria 1, 10125, Torino, Italy

\begin{abstract}
Ion Beam Analyses (IBA) techniques, for example PIXE (Particle Induced X-ray Emission) and IL (IonoLuminescence), are a powerful analytical tool used to investigate the composition and structure of materials in cultural heritage. These techniques could be applied both in vacuum, preparing the sample as in electron microscopy, and in air in a non-invasive way allowing to analyse artworks of practically any shape and dimension without sample preparation. Moreover the use of a focused beam (microbeam) permits to reach an analysis resolution of few micrometers in vacuum and ten micrometers in air.

In this work, instruments and methodologies are described and two examples of case study are reported: I) the mapping of elemental distribution in ancient roman coins; II) the trace elements measurement in lapis lazuli for provenance determination.
\end{abstract}

\section{Section: RESEARCH PAPER}

Keywords: Ion Beam Analysis; microbeam; trace elements; ancient coins; lapis lazuli

Citation: Alessandro Lo Giudice, Alessandro Re, Debora Angelici, Jacopo Corsi, Gianluca Gariani, Marco Zangirolami, Emma Ziraldo, lon Microbeam Analysis in cultural heritage: application to lapis lazuli and ancient coins, Acta IMEKO, vol. 6, no. 3, article 12, September 2017, identifier: IMEKO-ACTA-06 (2017)-03-12

Section Editor: Sabrina Grassini, Politecnico di Torino, Italy

Received March 15, 2017; In final form August 3, 2017; Published September 2017

Copyright: (C) 2017 IMEKO. This is an open-access article distributed under the terms of the Creative Commons Attribution 3.0 License, which permits unrestricted use, distribution, and reproduction in any medium, provided the original author and source are credited

Funding: This work was supported by University of Torino and INFN, Italy

Corresponding author: Alessandro Lo Giudice, e-mail: alessandro.logiudice@unito.it

\section{INTRODUCTION}

Ion Beam Analyses (IBA) are performed by using a proton beam provided by small accelerators as probe and collecting the products of the interaction between the particles and the atoms of the sample [1]. Depending on the applications and techniques, a broad beam (a few $\mathrm{mm}^{2}$ ) or a micro-beam $(2-20$ $\mu \mathrm{m}$ in diameter) could be used as probe; a scanning system permits to map the properties of the material under investigation in an area of about $2 \times 2 \mathrm{~mm}^{2}$ when micro-beam is employed. The energy of protons useful for IBA techniques is around $2-3 \mathrm{MeV}$ whereas the current is of the order of few hundreds of $\mathrm{pA}$, low enough to avoid any damage in the majority of the materials. IBA techniques can be carried out both in vacuum, preparing the sample as in electron microscopy, and in atmosphere, allowing the non-invasive analysis of objects such as artworks of practically any shape and dimension without sample preparation. Among the most used
IBA techniques RBS (Rutherford Back-Scattering), PIXE (Proton Induced X-Ray Emission), PIGE (Proton Induced Gamma-ray Emission), ERDA (Elastic Recoil Detection Analysis) and NRA (Nuclear Reaction Analysis) [1], [2] could be used in many scientific fields for elemental analysis, IL/IBIL (IonoLuminescence or Ion Beam Induced Luminescence) [3], [4] for characterization of optical properties of materials and IBIC (Ion Beam Induced Charge) [5] for the characterization of electronic properties of devices. In the cultural heritage field many of these techniques are used, though PIXE has a particular importance for the elemental composition analysis (especially for trace elements).

In this paper an application of micro-PIXE and IL (both micro-IL and broad beam) to solve outstanding archaeological issues is described. In particular two case studies are reported. The first is related to ancient silver-copper alloy coins from Roman and pre-Roman Italian cultures. The coins were studied 
by means of micro-PIXE to investigate their composition in function of the depth to obtain information on manufacturing and degradation processes. The second case study is related to provenance study of lapis lazuli, that is a blue semi-precious stone that has been used since Neolithic Era (VII millennium BC) for the manufacturing of precious carved artefacts. The aim was to identify the extraction sites of the rock obtaining information on ancient trade routes.

\section{INSTRUMENTS AND METHODS}

Ion beam analyses were carried out mainly by means of two scanning proton micro-beam lines at INFN (National Institute for Nuclear Physics) facilities having different acceleration voltages: the $2.5 \mathrm{MV}$ AN2000 accelerator at the Legnaro National Laboratory (INFN-LNL) in Padua (Figure 1) widely used for material characterization/modification and ion implantation [6]-[8] and the $3 \mathrm{MV}$ accelerator of the INFNLABEC Laboratory in Florence (Figure 2) widely used for multi-disciplinary studies [9]-[11]. In few cases also the in air AGLAE microbeam facility of the C2RMF in Paris was used [12].

Analyses at the micro-beam line in Legnaro are performed in a vacuum chamber. Therefore, the samples need to be prepared in a way similar to Scanning Electron Microscopy (SEM), i.e. a conductive carbon coating is applied (Figure 1). PIXE measurements were carried out both on coins and on lapis lazuli rocks using $2 \mathrm{MeV}$ protons and a current below $500 \mathrm{pA}$. The beam was below $5 \mu \mathrm{m}$ in diameter with a $3 \times 3 \mathrm{~mm}^{2}$ maximum scanning area.

In Florence, the measurements were carried out in air $(\mathrm{He}-$ flux) using a $3 \mathrm{MeV}$ proton beam and a current below $200 \mathrm{pA}$. The beam was of about $10 \mu \mathrm{m}$ in diameter with a $2 \times 2 \mathrm{~mm}^{2}$ maximum scanning area. Only lapis lazuli were analysed both by means of PIXE and IL. In the case of IL also the broad beam ion microscopy [13] was employed. Working in air the samples don't need any preparation and rocks or artworks of almost any shape and dimension can be analysed in a non-

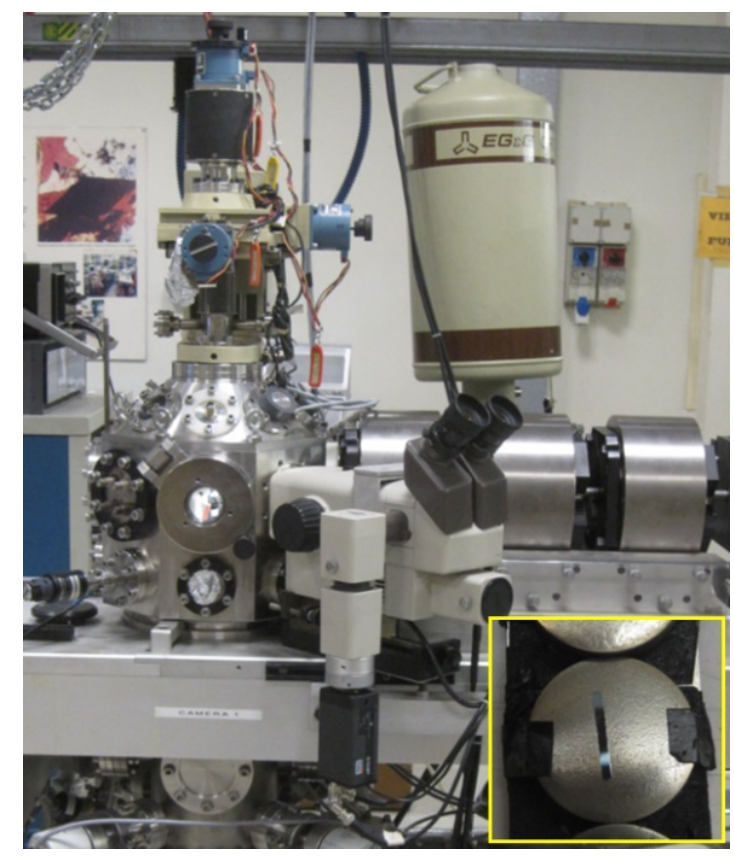

Figure 1. In vacuum analysis chamber at INFN-LNL laboratory and a coin sample cut, embedded in resin and covered with a carbon coating.

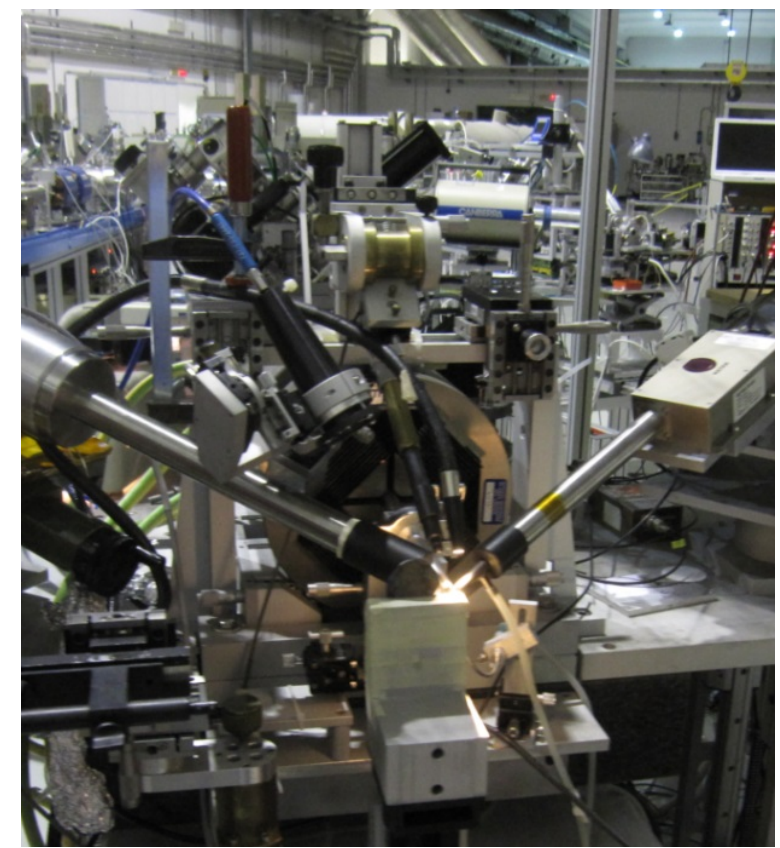

Figure 2. In air micro-beam line at INFN-LABEC laboratory during the analysis of a lapis lazuli artefact.

invasive way.

Both PIXE data acquired in Legnaro and in Florence were quantitatively analysed by means of GUPIXWIN (version 2.1.3) and by the use of a set of reference standards for the determination of the experimental parameters.

\section{CASE STUDIES}

\subsection{Ancient coins}

A study to analytically characterise ancient coins has been started in 2010. This topic is particularly interesting for numismatic and archaeometry, because it allows to evaluate commercial exchanges among tribes, to hypothesize relative chronologies, to verify the presence of a debasement along the years and to investigate the exchange ratios among different emissions of coins [14]. Until now the study has been focused on coins made of a silver-copper alloy in the Roman (Figure 3) and pre-Roman period. The main activity was carried out using neutron diffraction, neutron activation analysis and $\mathrm{p}-\mathrm{XRF}$, that are non-invasive techniques useful to measure the elements content [15]-[17].

The coins made in this material are often characterised by a surface layer with an $\mathrm{Ag}$ content higher than the bulk. To better study this surface silver-enriched layer, corrosion layers or inhomogeneity between surface and bulk, some silver coins have been chosen and prepared using a standard metallographic procedure, to analyse directly their section. At first, they have been cut with a rotating diamond wheel and their sections have
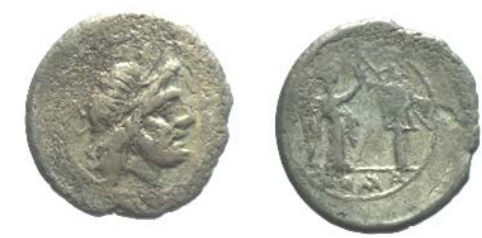

Figure 3. Obverse and reverse images of one of the investigated victoriatus JC1 (RRC: 166) 
been mounted in resin. Subsequently, surfaces were polished with papers having different grit and also with a diamond crystal paste (with grains 6-3-1 $\mu \mathrm{m}$ ). A carbon coating has then been applied to make the surfaces conductive. $\mu$-PIXE measurements were carried out in vacuum on these crosssections at the AN2000 microbeam facility of INFN-LNL.

$\mu$-PIXE elemental maps allow to analyse the distribution of major elements in few minutes, as shown for example in Figure 4. Thanks to this feature, the presence of a very thick surface silver-enriched layer (up to $250 \mu \mathrm{m}$ ) has been confirmed, for example, on a specific Roman coin emission: the Victoriati (4 samples analysed). All these coins are characterised by a silver content clearly higher in the surface layer and by peculiarities, such as for example the presence of voids, that suggest a probable intentional depletion occurred with acid chemicals before minting operations, as reported in other works [18]-[20]. This is a different process in respect of the production of suberatus coins where a copper core is wrapped with a silver foil.

Anyway, the added value of $\mu$-PIXE is the possibility to detect minor and trace elements inside the sample with a resolution of few micrometers. Similar techniques that make use of electron and X-ray beams show for some aspects lower performances than $\mu$-PIXE. Using SEM-EDS only $\mathrm{Cu}$ and $\mathrm{Ag}$ elements are detected due to the low sensitivity to trace elements, whereas $\mu$-XRF has a beam diameter greater than 10 $\mu \mathrm{m}$ and then a lower spatial resolution than $\mu$-PIXE. Moreover, although not used in this work, using proton beam, it is possible to carry out RBS analysis at the same time, which in some cases is capable of resolve the distribution of chemical elements in depth [21]. In Figure 5 typical PIXE spectra of the

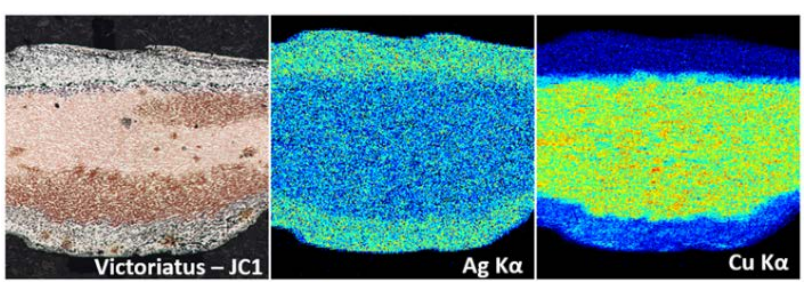

Figure 4. Optical microscopy section of a Victoriatus compared to $\mu$-PIXE maps (area $1.5 \times 1.5 \mathrm{~mm}^{2}$ ). external and internal regions of the coin are shown. The distribution of the elements along the section was measured, analysing small areas of about $40 \times 40 \mu \mathrm{m}^{2}$, recreating a profile of all the detected elements along the coin section, as shown e.g. in Figure $6 \mathrm{~b}$ for silver and copper in the same Victoriatus
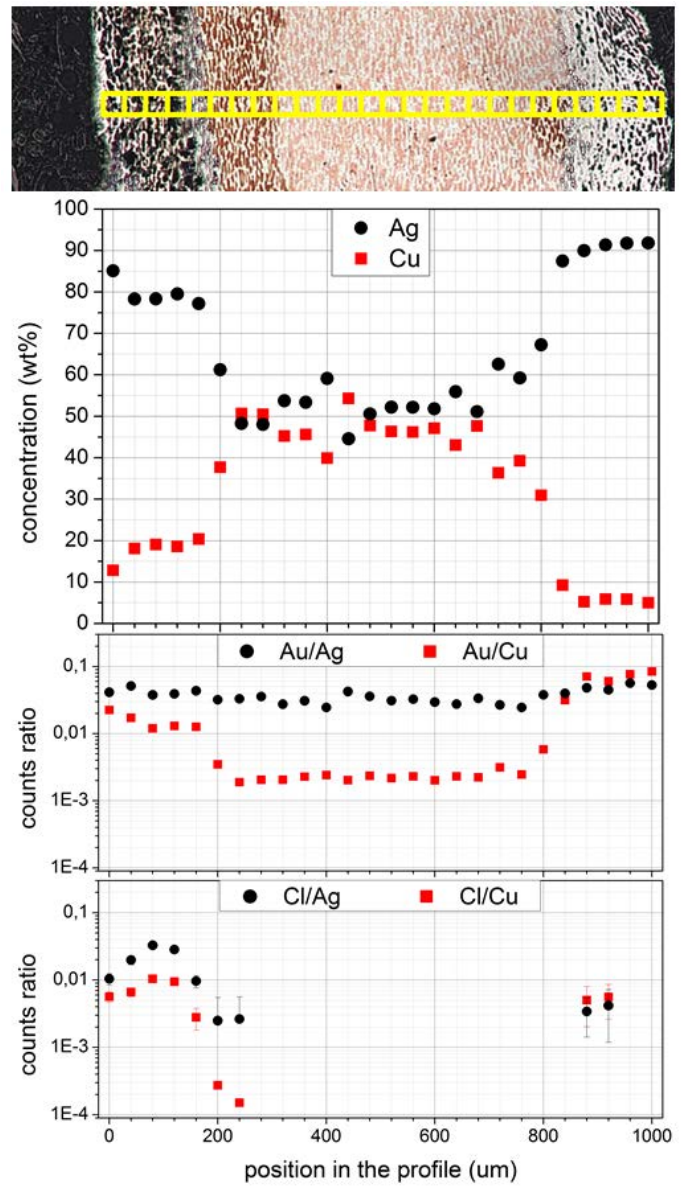

Figure 6. $\mu$-PIXE results of a profile of the same Victoriatus shown in Figure 3 and Figure 5 ; a) optical microscopy section showing the analysed areas (each yellow square is about $40 \times 40 \mu \mathrm{m}^{2}$ ); b) concentration profiles of the main elements ( $\mathrm{Ag}$ and $\mathrm{Cu}) ; \mathrm{c}$ ) ratio of peak areas $\mathrm{Au} / \mathrm{Ag}$ and $\mathrm{Au} / \mathrm{Cu}$; d) ratio of peak areas $\mathrm{Cl} / \mathrm{Ag}$ and $\mathrm{Cl} / \mathrm{Cu}$.

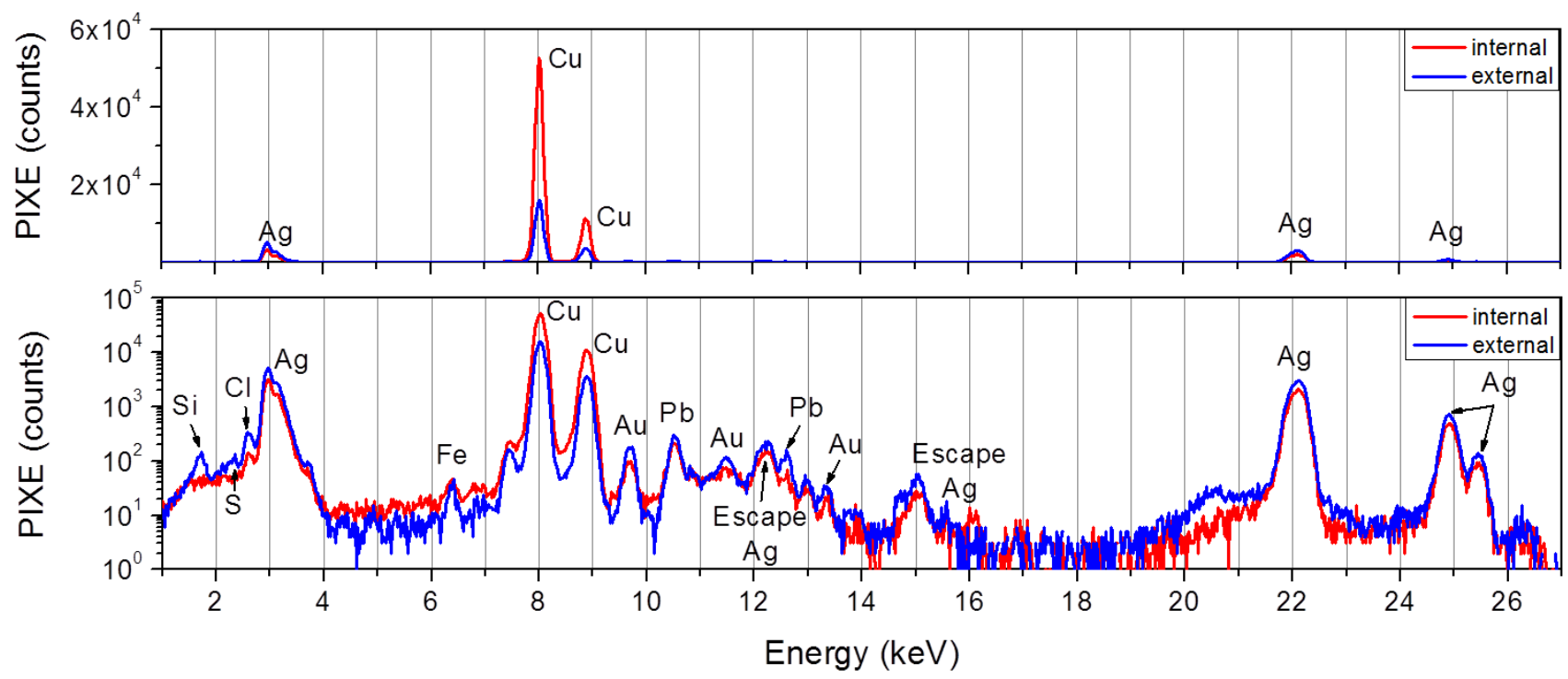

Figure 5. Example of PIXE spectra (in linear and in logarithmic scale) of internal and external regions of the Victoriatus shown in Figure 3 and Figure 4. 
Figure 3. The ratio minor element / main element (using the area of one of the main characteristic peaks) has been used to evaluate the correlation of each minor and trace element with the main ones (silver and copper). Some examples of the results are shown in Figure 6c and Figure 6d. In this way it is possible to understand where each element comes from: if the ratio on the main element is constant along the profile, one can suppose that the trace/minor element was present in the related raw material (for example gold in silver, Figure 6c). If both the ratios (on $\mathrm{Cu}$ and on $\mathrm{Ag}$ ) vary along the profile, the element is not correlated to the raw material (for example Chlorine in Figure $6 \mathrm{~d}$ ) but it could be entered in the coin during its burial time or during chemical treatments.

In this way important information was obtained on the analysed coins about the raw material used to mint them. In particular bromine, silicon, chlorine and iron were mainly detected close to the surface but not necessarily in strict correlation with the silver-enriched layer. This means that these elements, commonly present in soil and water, probably entered in the coin during its burial time and are not related to copper or silver ores. For example, in Figure 6d, it can be observed that in one side of the coin (right) chlorine is present only in two of the six areas related to the silver-enriched layer, whereas it is present in all the other side (left).

On the other hand, as expected, gold and lead were clearly linked to silver in all the coins we analysed but not to copper for which a correlation with nickel and zinc was observed. In Table 1 the values measured for two of the four Victoriati studied are shown; in this case Zn was under LOD (Limit Of Detection). Increasing the number of analysed samples, ratios can be used as a semi-quantitative way for provenance study of the raw material or as distinctive elements to identify production places and mints. In our case, for example, $\mathrm{Pb} / \mathrm{Ag}$ was observed to be up to 0.3 (one order of magnitude higher than observed in the two Victoriati of Table 1) in coins from other regions.

\subsection{Lapis lazuli}

Lapis Lazuli is a blue semi-precious stone that has been used since Neolithic Era (VII millennium BC) for the manufacturing of precious carved artefacts [22], [23]. The possibility to associate the raw material to man-made objects could help historians and archaeologists to reconstruct trade routes, especially for the ancient time when written testimonies are scanty or absent at all. To solve the issue we started in 2008 a long-term research, involving an interdisciplinary team. Due to the low probability of geological conditions in which it can be formed, only few sources of lapis lazuli exist in the world [24]. Until now, 45 lapis lazuli rocks from 4 quarry districts (Afghanistan, Tajikistan, Siberia and Chile) have been analysed, creating a database on this rock. The research has been focused in searching markers on single mineral phases using

Table 1. Ratio of minor/trace elements with main elements for two Victoriati coins. Victoriatus 1 is the same of Figures 3-6. For these coins $\mathrm{Zn}$ was under LOD (Limit Of Detection).

\begin{tabular}{ccc}
\hline $\begin{array}{c}\text { Elements } \\
\text { ratio }\end{array}$ & $\begin{array}{c}\text { Victoriatus 1 } \\
\text { (JC1) }\end{array}$ & $\begin{array}{c}\text { Victoriatus 2 } \\
\text { (JC13) }\end{array}$ \\
\hline $\mathrm{Au} / \mathrm{Ag}$ & $(37 \pm 9) \times 10^{-3}$ & $(25 \pm 3) \times 10^{-3}$ \\
$\mathrm{~Pb} / \mathrm{Ag}$ & $(23 \pm 3) \times 10^{-3}$ & $(29 \pm 5) \times 10^{-3}$ \\
$\mathrm{Ni} / \mathrm{Cu}$ & $(2.6 \pm 0.3) \times 10^{-3}$ & $(1.8 \pm 0.3) \times 10^{-3}$ \\
$\mathrm{Zn} / \mathrm{Cu}$ & Under LOD & Under LOD
\end{tabular}

microscopic techniques, which allow to observe and to analyse single crystals in a non-invasive way. On the basis of the markers found, a protocol was established [25] in which the luminescence properties and the quantification of trace elements in pyrite and diopside crystals play a crucial role in the provenance determination of lapis lazuli. The protocol was successfully applied on historical and archaeological objects from Medici's Collection (16 $6^{\text {th }}-18^{\text {th }}$ century) and from Ancient Egypt (first millennium BC) [25], [26]. It is not the aim of this paper to report all the markers of the protocol, but as an example diopside crystals of the Afghanistan rocks show higher quantity of titanium $(>710 \mathrm{ppm})$ or vanadium $(>210 \mathrm{ppm})$ or chromium $(>220 \mathrm{ppm})$ than Tajik samples or a strong ionoluminescence band at about $770 \mathrm{~nm}$. Otherwise only Siberian samples have a strontium content in diopside crystals higher than about $180 \mathrm{ppm}$.

In particular it was verified that all the markers found (presence of a mineralogical phase, peculiar trace elements inside pyrite or diopside crystals, luminescence bands) are simultaneously detectable by means of ion beam analysis techniques, in particular $\mu$-PIXE [18] and IL. Moreover, IBA techniques are very suitable techniques because if applied in air are non-invasive methods usable on precious archaeological objects, contrarily to other techniques used in provenance studies that need a sampling and are destructive [28], [29].

Also $\mu$-XRF have produced good results [30], but limited to elemental analysis because X-ray luminescence (XRL) is normally not present in benchtop instruments. Moreover XRF allows to analyse only relatively large crystals (more than about $100-150 \mu \mathrm{m}$ in diameter, not always available in archaeological objects) due to the beam dimension and to the higher depth of analysis with respect to IBA techniques that are able to analyse crystals down to $20-50 \mu \mathrm{m}$ in diameter. For example, in Figure 7 the PIXE map of a portion (about $125 \times 125 \mu \mathrm{m}^{2}$ ) of lapis lazuli is shown in which a pyrite crystal $\left(\mathrm{FeS}_{2}\right)$ is visible, that is characterized by the presence of selenium and the absence of copper (under the limit of detection). A content of selenium in pyrite crystals higher than $40 \mathrm{ppm}$ is a marker for a Chilean provenance of lapis lazuli [27]. Such result cannot be obtained neither by means of $\mu$-XRF due to the small dimension of the crystal, nor by means of SEM-EDS because the nickel and selenium contents are too low to be detected.

Table 2 shows another typical result in element quantification, obtained by means of SEM-EDS and $\mu$-PIXE on the diopside crystal shown in Figure 8. All the trace elements, that are the only usable for provenance

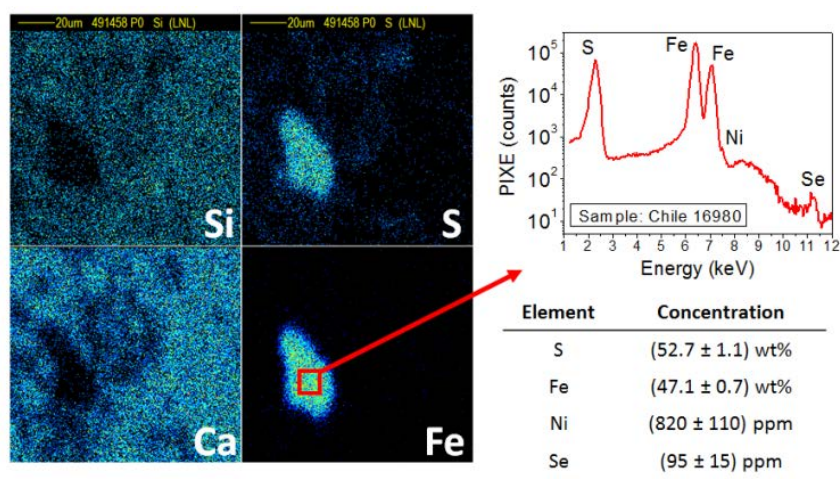

Figure 7. $\mu$-PIXE map of some elements in a lapis lazuli from Chile (sample Chile 16980), $\mu$-PIXE spectrum of a pyrite crystal and elements content. 
Table 2. Element contents in diopside mineralogical phase shown in Figure 8 obtained by means of SEM-EDS and $\mu$-PIXE analysis.

\begin{tabular}{lcc}
\hline Element & $\begin{array}{c}\text { SEM-EDS } \\
\text { (wt\%) }\end{array}$ & $\begin{array}{c}\boldsymbol{\mu} \text {-PIXE } \\
\text { (wt\%) }\end{array}$ \\
\hline $\mathrm{Na}$ & $0.4 \pm 0.1$ & $\begin{array}{c}\text { Not observable } \\
\mathrm{Mg}\end{array}$ \\
$\mathrm{Al}$ & $0.8 \pm 0.1$ & $10.3 \pm 0.3$ \\
$\mathrm{Si}$ & $26.3 \pm 0.2$ & $0.7 \pm 0.1$ \\
$\mathrm{Ca}$ & $18.2 \pm 0.1$ & $26.1 \pm 0.3$ \\
$\mathrm{O}$ & $43.9 \pm 0.2$ & $44.8 \pm 0.2$ \\
& & \\
\hline $\mathrm{Element}$ & SEM-EDS & $\boldsymbol{\mu}$-PIXE \\
& (ppm) & (ppm) \\
\hline $\mathrm{S}$ & Under LOD & $480 \pm 50$ \\
$\mathrm{Cl}$ & Under LOD & $330 \pm 40$ \\
$\mathrm{~K}$ & Under LOD & $550 \pm 30$ \\
$\mathrm{Ti}$ & Under LOD & $1260 \pm 50$ \\
$\mathrm{~V}$ & Under LOD & $500 \pm 40$ \\
$\mathrm{Cr}$ & Under LOD & $170 \pm 20$ \\
$\mathrm{Mn}$ & Under LOD & $280 \pm 20$ \\
$\mathrm{Fe}$ & Under LOD & $480 \pm 20$ \\
$\mathrm{Sr}$ & Under LOD & $28 \pm 14$ \\
$\mathrm{Zr}$ & Under LOD & $220 \pm 40$ \\
\hline
\end{tabular}
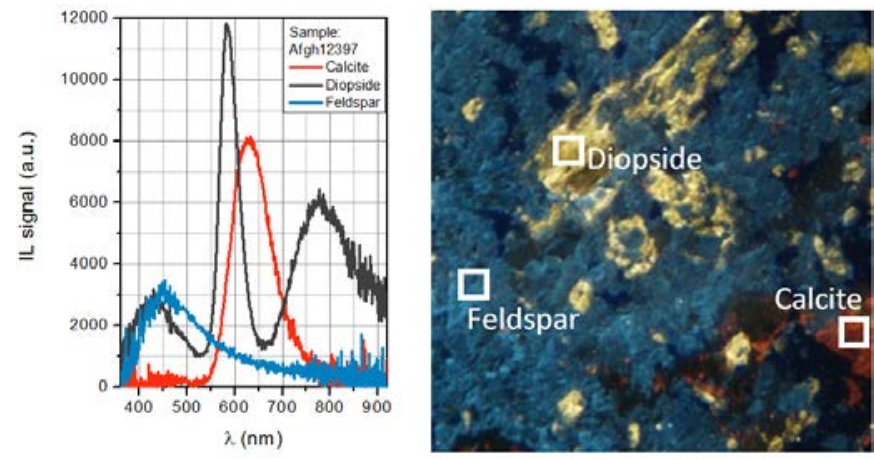

Figure 8. Cold-Cathodoluminescence image, about $1.3 \times 1.3 \mathrm{~mm}^{2}$ (right), and $\mu$-IL spectra (left) of an Afghan lapis lazuli (sample Afgh12397). Each mineralogical phase is characterized by a different emission spectrum.

determination, are measurable only by means of $\mu$-PIXE analysis. In this sample, the features of an Afghan provenance of the rock are evident, i.e. the high content in titanium and vanadium and the low quantity of strontium [26].

Recently, to increase the markers, the trace element analysis by means of $\mu$-PIXE was extended to other mineralogical phases in addition to diopside and pyrite, in particular to calcite and feldspar that are easily recognizable in a lapis lazuli by means of their ionoluminescence properties. In fact, as shown in Figure 8, calcite shows a strong red luminescence at about $625 \mathrm{~nm}$ whereas feldspar has a characteristic blue luminescence centered at about $450 \mathrm{~nm}$

\section{CONCLUSIONS}

Thanks to the use of IBA techniques it is possible to measure the elemental composition and luminescence properties of materials in cultural heritage with a micrometric resolution and, if necessary, in a non-invasive way using in-air facilities. This is very useful to answer many of the questions posed by archaeologists, art historians and restorers. Similar techniques that make use of electron and X-ray beams show for some aspects lower performances than IBA and in many cases are not able to solve adequately the issues.

In this paper it was shown how the use of IBA techniques has been suitable to contribute in solving two archaeological issues. $\mu$-PIXE analysis carried out on ancient Roman and preRoman coins was useful to know their composition in function of the depth. In particular the profile of the silver-enriched layer has been reconstructed inside the coin obtaining information on manufacturing and degradation processes. Moreover trace elements have been associated to the contaminants of the soil $(\mathrm{Br}, \mathrm{Si}, \mathrm{Cl}, \mathrm{Fe})$ or to the raw minerals $(\mathrm{Pb}, \mathrm{Au}$ in silver; $\mathrm{Ni}, \mathrm{Zn}$ in copper). Finally the ratios $\mathrm{Pb} / \mathrm{Ag}$, $\mathrm{Au} / \mathrm{Ag}, \mathrm{Ni} / \mathrm{Cu}$ and $\mathrm{Zn} / \mathrm{Cu}$ have been measured and they will be used in future works to identify production places and mints or provenance of raw materials.

About lapis lazuli a protocol to identify the provenance of the stone used for carved artefacts has been carried out. It is based on the measurement of trace elements and luminescence properties of minerals inside lapis lazuli at a micrometric scale. Currently the protocol is completely applicable only by means of IBA techniques, in particular $\mu$-PIXE an IL analysis, also on precious objects. It has been successfully applied on artworks and in particular on precious carved objects from Ancient Egypt (first millennium BC). At now all the analysed objects are ascribable to Afghanistan (Badakhshan Province) that is a further confirmation of trading of this stone up to $4000 \mathrm{~km}$ from its extraction site in the first millennium BC.

\section{ACKNOWLEDGEMENT}

The authors wish to acknowledge Silvia Calusi, Nicla Gelli, Lorenzo Giuntini, Mirko Massi, Francesco Taccetti, as the experts of the external scanning microbeam line at INFNLABEC Laboratory; Leonardo La Torre, Valentino Rigato as the experts of the in vacuum microbeam line at INFN-LNL Laboratory; Thomas Calligaro, Claire Pacheco, Quentin Lemasson, Laurent Pichon, Brice Moignard as the experts of the external scanning microbeam line at CNRS-AGLAE Laboratory; Giovanni Pratesi, Maria Cristina Guidotti for having made available the lapis lazuli samples and objects. The authors wish to warmly thank CHNet, the INFN network of laboratories working in the Cultural Heritage field, for supporting this research, both in terms of instrumentations, competencies and grants. Moreover, the INFN experiment CHNet-imaging is acknowledged with gratitude.

\section{REFERENCES}

[1] M.B.H. Breese, D.J. Jamieson, P.J.C. King, "Materials Analysis using a nuclear microprobe", John Wiley \& Sons, New York, (1996)

[2] S.A.E. Johansson, J.L. Campbell, K.G. Malmqvist, Particle Induced X-Ray Emission Spectrometry (PIXE), John Wiley \& Sons, Inc. Chichester, UK, 1995, ISBN 0-471-58944-6.

[3] Malmqvist KG, Elfman M, Remond G, Yang C, PIXE and ionoluminescence - A synergetic analytical combination, Nucl Instrum Method B 109/110 (1996) 227 - 233

[4] C. Manfredotti, S. Calusi, A. Lo Giudice, L. Giuntini, M. Massi, P. Olivero, A. Re, Luminescence centers in proton irradiated single crystal CVD diamond, Diam. Relat. Mater. 19 (2010) pp. 854-860.

[5] P. Olivero, J. Forneris, M. Jaksic, Z. Pastuovic, F. Picollo, N. Skukan, E. Vittone, Focused ion beam fabrication and IBIC 
characterization of a diamond detector with buried electrodes Nucl Instr Meth B 269 (2011) pp. 2340-2344

[6] D. Bollini, F. Cervellera, G.P. Egeni, P. Mazzoldi, G. Moschini, P. Rossi, V. Rudello, The microbeam facility of the AN-2000 accelerator of the Laboratori Nazionali di Legnaro, Nucl Instr Meth A 328(1-2) (1993) pp. 173-176.

[7] F. Bosia, N. Argiolas, M. Bazzan, B.A. Fairchild, A.D. Greentree, D.W.M. Lau, P. Olivero, F. Picollo, S. Rubanov, S. Prawer, Direct measurement and modelling of internal strains in ionimplanted diamond, J. Phys.: Condens. Matter 25 (2013), 385403.

[8] F. Picollo, A. Battiato, E. Carbone, L. Croin, E. Enrico, J Forneris, S. Gosso, P. Olivero, A. Pasquarelli, V. Carabelli, Development and Characterization of a Diamond-Insulated Graphitic Multi Electrode Array Realized with Ion Beam Lithography, Sensors 15 (2015), pp. 515-528

[9] S. Calusi, The External Ion Microbeam of the LABEC Laboratory in Florence: Some Applications to Cultural Heritage, Microsc. Microanal. 17 (2011) pp. 661-666.

[10] F. Taccetti, L. Giuntini, G. Casini, A.A. Stefanini, M. Chiari, M.E. Fedi, P.A. Mandò, The pulsed beam facility at the $3 \mathrm{MV}$ Van de Graaff accelerator in Florence: Overview and examples of applications, Nucl Instr Meth B 188 (2002) 278-284

[11] L. Giuntini, M. Massi, S. Calusi, N. Gelli, L. Castelli, L. Carraresi, C. Czelusniak, M.E. Fedi, A.M. Gueli, L. Liccioli, P.A. Mandò, A. Mazzinghi, L. Palla, C. Ruberto, F. Taccetti, The set-up for forward scattered particle detection at the external microbeam facility of the INFN-LABEC laboratory in Florence, Nucl Instr Meth B 348 (2015) pp. 8-13

[12] L. Pichon, B. Moignard, Q. Lemasson, C. Pacheco, P. Walter, Development of a multi-detector and a systematic imaging system on the AGLAE external beam, Nucl Instrum Meth B 318(A) (2014) 27-31

[13] A. Lo Giudice, A. Re, D. Angelici, S. Calusi, N. Gelli, L. Giuntini, M. Massi, G. Pratesi, In-air broad beam ionoluminescence microscopy as a tool for rocks and stone artworks characterisation", Anal Bioanal Chem 404(1) (2012) pp. 277-281.

[14] A. Pautasso, Le monete preromane dell'Italia settentrionale, Centro di Studi Preistorici e Archeologici di Varese (1966) Varese

[15] J. Corsi, B. Maróti, A. Re, Z. Kasztovszky, L. Szentmiklósi, M. Torbágyi, A. Agostino, D. Angelici, S. Allegretti, Compositional analysis of a historical collection of Cisalpine Gaul's coins kept at the Hungarian National Museum, J. Anal. Atom. Spectrom. 30(3) (2015) pp. 730-737.

[16] J. Corsi, F. Grazzi, A. Lo Giudice, A. Re, A. Scherillo, D. Angelici, S. Allegretti, F. Barello, Compositional and microstructural characterization of Celtic silver coins from northern Italy using neutron diffraction analysis, Microchem. J. 126 (2016) pp. 501-508.

[17] J. Corsi, A. Lo Giudice, A. Re, A. Agostino, F. Barello, Potentialities of X-ray fluorescence analysis in numismatics: the case study of pre-Roman coins from Cisalpine Gaul, Archaeol Anthropol Sci (2017) DOI:10.1007/s12520-016-0371-7

[18] L. Beck, S. Bosonnet, S. Réveillon, D. Eliot, F. Pilon, Silver surface enrichment of silver-copper alloys: a limitation for the analysis of ancient silver coins by surface techniques, Nucl. Instr. Meth. B 226 (2004), pp. 153-162.

[19] F.J. Ager, A.I. Moreno-Suárez, S. Scrivano, I. Ortega-Feliu, B. Gómez-Tubío, M.A. Respaldiza, Silver surface enrichment in ancient coins studied by micro-PIXE, Nucl Instr Meth B 306 (2013) pp.241-244

[20] F.P. Romano, S. Garraffo, L. Pappalardo, F. Rizzo, In situ investigation of the surface silvering of late Roman coins by combined use of high energy broad-beam and low energy micro-beam X-ray fluorescence techniques, Spectrochimica Acta Part B 73 (2012) pp. 13-19

[21] C. Fourdrin, S. Pagès Camagna, C. Pacheco, M. Radepont, Q. Lemasson, B. Moignard, 1.Pichon, B. Bourgeois, V. Jeammet, Characterization of gold leaves on Greek terracotta figurines: a PIXE-RBS study, Microchemical Journal 126 (2016) pp. 446453

[22] M. Casanova, Le lapis-lazuli dans l' Orient Ancien: production et circulation du Néolithique au IIe millénaire av. J.-C. Editions du Comité des travaux historiques et scientifiques, (2013) Paris

[23] G. Hermann, Lapis lazuli: the early phases of its trade. Iraq 30(1) (1968) 21-57

[24] L. Von Rosen, Lapis lazuli in geological contexts and in ancient written source. Studies in Mediterranean Archaeology and Literature, 65; ed. by Paul Astroms forlag, Partille (1988) Sweden

[25] A. Lo Giudice, D. Angelici, A. Re, G. Gariani, A. Borghi, S. Calusi, L. Giuntini, M. Massi, L. Castelli, F. Taccetti, T. Calligaro, C. Pacheco, Q. Lemasson, L. Pichon, B. Moignard, G. Pratesi, M.C. Guidotti, Protocol for lapis lazuli provenance determination: evidence for an Afghan origin of the stones used for ancient carved artefacts kept at the Egyptian Museum of Florence, Archaeol. Anthropol. Sci. 9 (4) (2017) pp. 637-651

[26] A. Re, D. Angelici, A. Lo Giudice, J. Corsi, S. Allegretti, A.F. Biondi, G. Gariani, S. Calusi, N. Gelli, L. Giuntini, M. Massi, F. Taccetti, L. La Torre, V. Rigato, G. Pratesi, Ion Beam Analysis for the provenance attribution of lapis lazuli used in glyptic art: the case of the "Collezione Medicea", Nucl Instr Meth B 348 (2015) pp. 278-284.

[27] A. Re, D. Angelici, A. Lo Giudice, E. Maupas, L. Giuntini, S. Calusi, N. Gelli, M. Massi, A. Borghi, L.M. Gallo, G. Pratesi, P.A. Mandò, New markers to identify the provenance of lapis lazuli: trace elements in pyrite by means of micro-PIXE, Appl. Phys. A-Mater. 111(1) (2013) pp. 69-74.

[28] R. Law, Evaluating potential lapis lazuli sources for ancient South Asia using sulfur isotope analysis. In: Lamberg-Karlovsky CC, Genito B(eds) " My life is like the summer rose " Maurizio Tosi e l'archeologia come modo di vivere. Archaeopress, Oxford (2014) pp. $419-429$

[29] M. Ganio, M. Gulmini, K. Latruwe, F. Vanhaecke, P. Degryse, Sasanian glass from Veh Ardaš̄ir investigated by strontium and neodymium isotopic analysis, Journal of Archaelogical Science 40 (2013) pp. 4264-4270

[30] D. Angelici, A. Borghi, F. Chiarelli, R. Cossio, G. Gariani, A. Lo Giudice, A. Re, G. Pratesi, G. Vaggelli, $\mu$-XRF analysis of trace elements in lapis lazuli-forming minerals for a provenance study, Microsc. Microanal. 21(2) (2015) pp. 526-533. 